\section{4!}

University of

HUDDERSFIELD

Inspiring tomorrow's professionals
South West Yorkshire Partnership W/HS

NHS Foundation Trust

Mental Health and Learning Disabilities Research and Practice

Volume 7 Number 1

Spring 2010

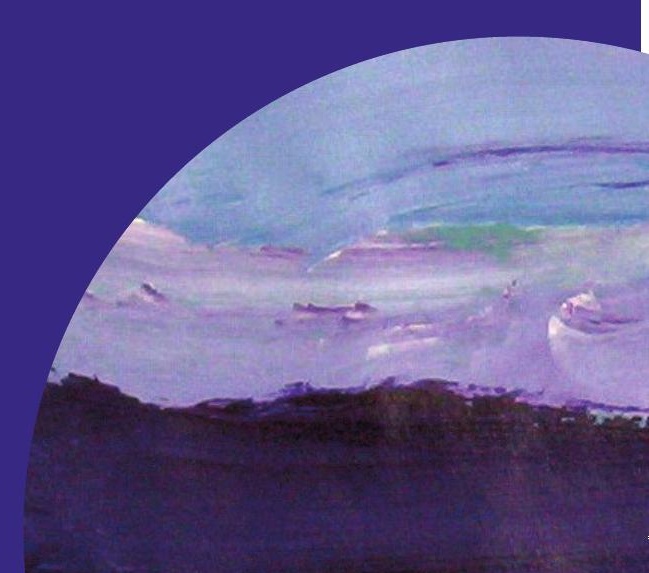


The Feelings Group: A Quantitative and Qualitative Evaluation of the Outcomes of a Smaller Anger Management Group for Clients who have a Learning Disability

$$
\text { Richard Smith }{ }^{1} \& \text { Sarah Jeffrey }{ }^{1}
$$

Submitted for the Tim Lister Psychological Therapies Essay Prize

1 Bedfordshire \& Luton Mental Health \& Social Care Partnership NHS Trust 


\title{
'The Feelings Group': Quantitative and Qualitative Evaluation of the Outcomes of a Smaller Anger Management Group for Clients who have a Learning Disability
}

\author{
Richard Smith, Sarah Jeffrey
}

\section{Introduction}

Referrals concerning problems with anger for people with learning disability (LD) are relatively common as they are thought to be prone to difficulty in managing their anger (Willner, et al., 2002), a problem associated with aggressive behaviour (Novaco, 1994). Aggression is also prevalent in this population, with obvious inherent risks to themselves and others (Harris, 1993; Kiely \& Pankhurst, 1998).

Research on direct therapy in people with a learning disability (LD) indicates that there was a period of disdain for these types of approaches (Sinason, 1992). This was followed by a period marked by doubt around the value of using cognitive principles in particular (Willner, 2006), which was eventually overcome by a more positive and less discriminatory approach (Willner, 2005). This hesitancy has delayed the generation of robust empirical evaluation, which has yet to catch up (Willner, Jones, Tams \& Green, 2002). The guidelines from the NHS are then activated whereby "in the absence of well-designed randomised trials, clinicians may legitimately draw upon analysis of expert opinion and past experience" (Department of Health, 1996; p26). In some ways this offers freedom to adopt novel approaches or ones adapted from principle applied in other areas of clinical work, however, it also represents a difficulty in operating using evidence-based practice (Willner, 2005), which to some may represent a 'professional minefield' (Mead, 2000).

In the emergent evidence-base for interventions for anger in this group, one important distinction has been made between 'anger management' and 'anger treatment' (Novaco et al., 2000), where the former is seen as a psycho-educational approach whilst the latter explicitly combines assessment with treatment. Anger treatment also "centrally involves substantial cognitive restructuring and the acquisition of arousal reduction and behavioural coping skills" (Rose, et al., 2000, p172)

This article presents the results from a small anger-management group for clients with a learning disability that was to be called "The Feelings Group", which was based on the "Self-awareness group" resource pack from Willner \& Tomlinson (Psychology Department, Learning Disabilities Directorate, Bro Morgannwg NHS trust). This intervention boasted effectiveness in an RCT evaluation published in an article by Willner and colleagues (2002).

The data was taken as part of service evaluation for the group. Informed consent was given by the clients involved to write about the group in an article.

\section{Plan}

In reviewing the literature for approaches to anger problems in people with learning disabilities, it is evident that it is a field just starting the challenge of catching up with the respective evidence-base of Mental Health treatment approaches (Willner, et al., 2002). 
A CBT model based on Novaco $(1975 ; 1979)$ is a widely adopted approach in the treatment of anger in people with learning disabilities. Regarding anger as having three constituent components of physiology, behaviour and cognitions, the model is therapeutically applied by addressing these aspects of anger through relaxation, coping skills, and cognitive restructuring, respectively (Willner et al., 2002).

This approach has received some support in single case studies (Black \& Novaco, 1993), and small groups (Benson et al., 1986; Moore et al., 1997) with no control measures. There has also been a non-randomized controlled (Rose et al., 2000) and a randomised controlled trial (Willner et al., 2002), the latter being considered the gold standard for treatment evaluation (Department of Health, 1996).

The group was based on the "Self-awareness Group" resource pack by Willner \& Tomlinson (Bro Morgannwg NHS trust), a package of 11 2-hour sessions of CBT based treatment for anger that was evaluated in an article by Willner and colleagues (2002).

The group described in this article consisted of 15 weekly 1-hour sessions (with a half-time 5 minute break). The prescribed number of sessions had been acknowledged as a guideline and that additional sessions may be necessary according to the pace set by the group. This was especially important since one hour rather than the prescribed two hours had been allocated as a suitable session length, based on capacity to maintain attention and optimised learning (Baddeley \& Longman, 1978).

Two facilitators (a trainee Clinical Psychologist and an Assistant Psychologist, one female, one male) ran the group. Criteria for facilitators were being quick-thinking, flexible and able to respond to multiple demands, sufficiently extrovert to feel comfortable with role-playing, commitment to the running of the whole course and having an understanding of principles on which the course is based. They were both prepared to spend time in preparing for the group and would work well together.

\section{Participants}

Late in 2007 Services for people with learning disabilities (SPLD) had received an increase in the number of referrals requesting anger management. It was agreed that psychology referrals were screened by a Clinical Psychologist during triage for eligibility to attend The Feelings Group, using the criteria suggested by the resource pack for the 'Self Awareness Group'. These were the client having a problem with anger, having an IQ of 50 to 70 and not using anger 'instrumentally' (i.e. for a desired effect).

If The Feelings Group was considered a suitable option, then the client was given an appointment with one of the group facilitators to talk about the group. Since the clinical assessment had been completed and the group would involve exploration of anger, this assessment focused on suitability. The inclusion and exclusion criteria for this assessment were sufficient verbal ability, a preliminary notion or openness to the idea of emotion and cognitions, and motivation to change, as described by Willner (2006).

However, it was difficult to predict how people were going to respond to the group from one-to-one discussions with them. The first group session was designed to be an introductory 'ice-breaking' session and allow a further assessment of how people respond to the group context and the group tasks. 
6 participants attended the ice breaking session. One client declined the group after this due to a recent bereavement. Another client (who had traits of Autism Spectrum Disorder [ASD]) was deemed unsuitable due to her extreme difficulty in discussing the current topic in a relevant manner and the group did not fit into her wellestablished routine. A third client intended to attend the group but his time keeping skills meant that he missed the first four weeks of the group and then, in a phone call, he stated he did not have a problem with anger management.

The three remaining participants were as follows (their names have been changed to ensure anonymity):

Lee was a 26 year old white British man with a mild learning disability. He had previously undergone individual CBT for anger problems 2 years previously, with positive outcomes. He reported he lost his temper in numerous situations but his particular difficulties lay in volatile relationships with his family members, with whom he lived with.

Susan was a 39 year old white British lady with a mild to moderate learning disability. She had previously undergone and disengaged from individual CBT sessions, which were for low mood and alcohol abuse. Her recent difficulties with anger were thought to be a result of on-going contact difficulties with her children and a difficult relationship with her new husband.

Rosa was a 25 year old Italian/white British lady with a mild learning disability, epilepsy and ASD. She had had no previous psychological intervention. She would most commonly lose her temper when plans changed or when her sister borrowed something or changed the TV channel. Her anger also had a low mood component to it, with some associated self-harm.

\section{Intervention}

The introductory session was attended by all six members and facilitated by both aforementioned facilitators, along with a clinical psychologist supervising the group. The main content of this session was: introducing the group, including what it entailed, what people's worries were about the group, the clients brainstorming what the group rules should be and a brief introductory chat about anger.

All sessions began with a warm up exercise and were punctuated by a drinks break. They all ended with a relaxation exercise, which was increasingly led by the clients. All clients were given a relaxation CD made by the psychology department of SPLD. On the $C D$ a narrator described instructions for progressive relaxation over a soundtrack of soothing music.

Topics addressed during sessions included, in chronological order:

- triggers that evoke anger;

- physiological and behavioural components of anger;

- behavioural techniques to avoid the build up of anger and for coping with anger provoking situations;

- later, cognitive techniques;

- and finally, assertiveness;

Presentation mainly consisted of the clients brainstorming ideas (e.g. for the triggers or for personalised ways to implement coping strategies) and then in later sessions, 
role play. Extensive revision of previous ideas occurred in every session and the clients were asked upon to do this increasingly without the aid of the facilitators.

From the first session, clients were given homework assignments, or 'hassle logs'. In these, the clients described, analysed and evaluated a situation in which they had become angry. In subsequent sessions, clients were invited to read out their hassle logs and the group evaluated how the person coped, in a supportive and encouraging way.

Throughout the sessions, visual and pictorial aides as well as client involvement were used heavily to increase interest and augment memory. Examples of this include: fizzing up a bottle of sparkling water to represent how anger can build up until it bursts out, an outline of a person with moveable cut-out body parts to show the physiological changes caused by anger, a game of 'Snap' using cards with faces on showing various emotions to increase emotional awareness and making up posters of people's memories of a time they've been happy to aid relaxation.

Materials were given to the clients after the follow up session to help them remember the techniques learnt within the sessions. These consisted of a poster with a representation of a time the client felt at their happiest (to be used with relaxation), a poster of the 'Top Ten' coping strategies (made after brainstorming by the clients) and a key ring with flashcards of the 'Top Ten'. They kept the relaxation CD to be used in the future too.

\section{Assessment and Evaluation}

In the time between the 'ice-breaking' session and the first session, the clients and someone who knew them well were interviewed using a questionnaire, which were supplied with the resource pack. This was done separately to avoid any bias. This was then repeated after the $15^{\text {th }}$ (and last) session. The questionnaire used was the Provocation Index (PI).

The $\mathrm{PI}$ is completed to obtain an overall estimate of how much and how frequently a person becomes angry in 25 day-to-day situations at the time of the assessment. Scores on the PI have been shown to correlate with staff reported levels of aggression (Rose \& West, 1999). It rates the intensity of anger felt in each situation on a 4 point scale (0-not, 1-little, 2-fairly, 3-very) and the frequency of anger on a 5 point scale (0-less than once a month, 1-once a month, 2-once a week, 3-once a day, 4-many times a day). Clients were only asked about the intensity of the anger felt in each situation while the carers were asked both the frequency and the intensity.

The mean score of the 25 situations was then calculated for the 3 questionnaires (self report intensity, carer report intensity and carer report frequency). The results can be seen in Tables 1 and 2 and Graphs 1-3. 
Table 1. Client and Carer Ratings of intensity of Anger Before and After the Group

\begin{tabular}{|l|l|l|l|l|}
\hline & \multicolumn{2}{|l|}{ Client rating } & \multicolumn{2}{l|}{ Carer rating } \\
\hline & Pre & Post & Pre & Post \\
\hline Susan & 2.12 & 2 & 1.35 & 1.04 \\
\hline Rosa & 1.64 & 1.32 & 1.6 & 1.28 \\
\hline Lee & 2.88 & 2.4 & 2.88 & 1.28 \\
\hline Mean & $\mathbf{2 . 2 1}$ & $\mathbf{1 . 8 1}$ & $\mathbf{1 . 9 4}$ & $\mathbf{1 . 2}$ \\
\hline
\end{tabular}

Graph 1. Client Ratings of Intensity of Anger Before and After the Group

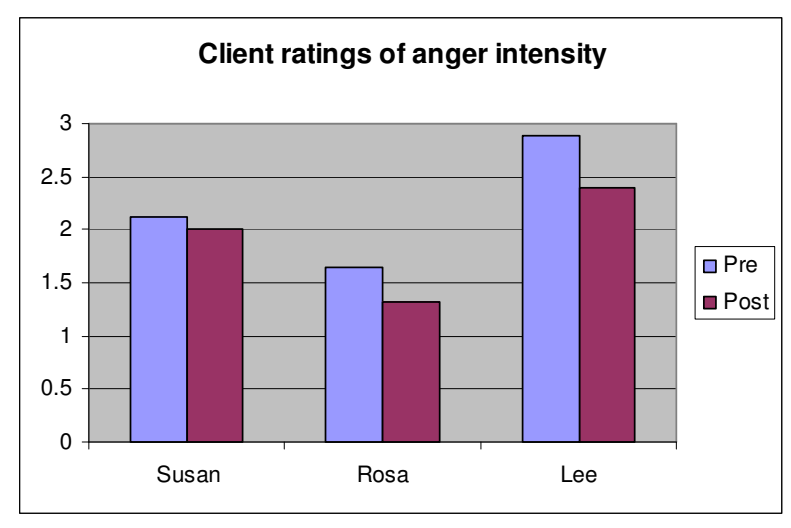

Graph 2. Carer ratings of Intensity of Anger Before and After the Group

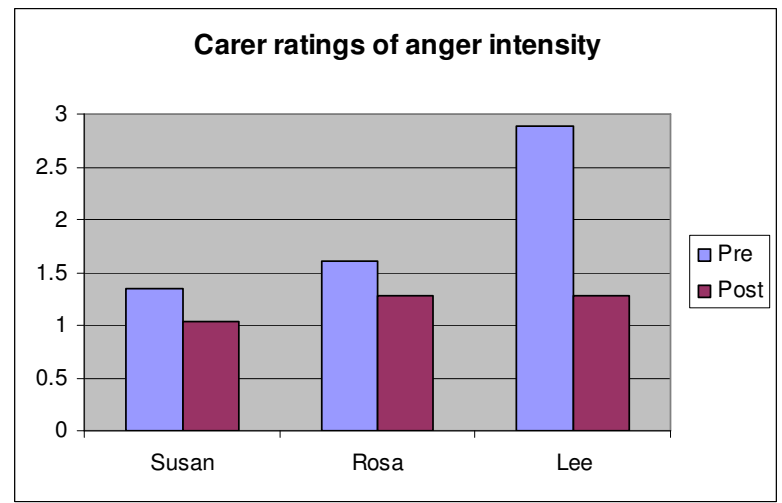

Table 2. Carer Ratings of Frequency of Anger Before and After the Group

\begin{tabular}{|l|l|l|}
\hline \multirow{2}{*}{ Client } & \multicolumn{2}{|l|}{ Carer ratings } \\
\cline { 2 - 3 } & Pre & Post \\
\hline Susan & 0.72 & 0.20 \\
\hline Rosa & 0.32 & 0.16 \\
\hline Lee & 1.40 & 0.88 \\
\hline Mean & $\mathbf{0 . 8 1}$ & $\mathbf{0 . 4 1}$ \\
\hline
\end{tabular}


Graph 3. Carer Ratings of Frequency of Anger Before and After the Group

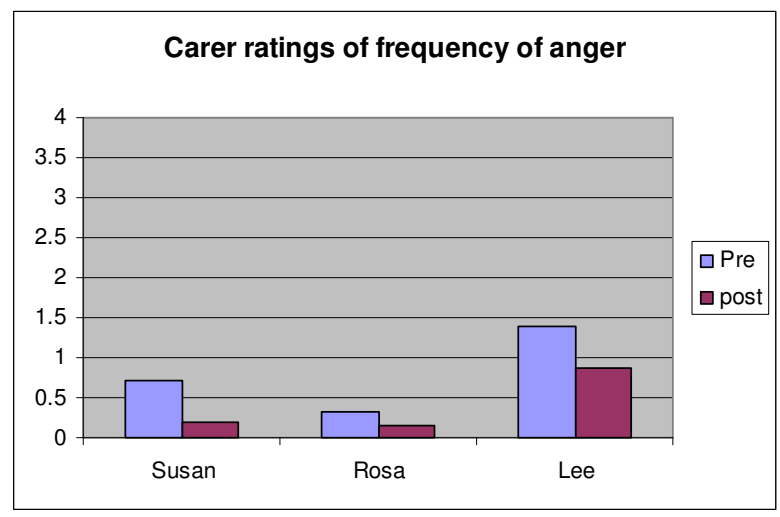

The results were compared to those found in the Willner et al. (2002) paper. Only intensity of anger, and not frequency, was measured by the PI in Willner study however. The means from the PI (intensity) current study and Willner study can be seen Table 3 and Graph 4:

Table 3. Comparing the Means of the Pre and Post Client-Report and carer-report scores for the PI (intensity) Between the Current Study and the Willner et al. (2002) study

\begin{tabular}{|c|c|c|c|c|c|c|c|}
\hline \multicolumn{4}{|c|}{ Rated by client } & \multicolumn{4}{|c|}{ Rated by carer } \\
\hline \multicolumn{2}{|c|}{ Pre-Group } & \multicolumn{2}{|c|}{ Post-Group } & \multicolumn{2}{|c|}{ Pre-Group } & \multicolumn{2}{|c|}{ Post-Group } \\
\hline Current & Willner & Current & Willner & Current & Willner & Current & Willner \\
\hline 2.21 & 1.71 & 1.81 & 1.28 & 1.94 & 1.72 & 1.2 & 1.21 \\
\hline
\end{tabular}

Graph 4. Comparing the Means of the Pre and Post Client-Report and Carer-Report Scores for the PI between the Current Study and the Willner et al. (2002) study

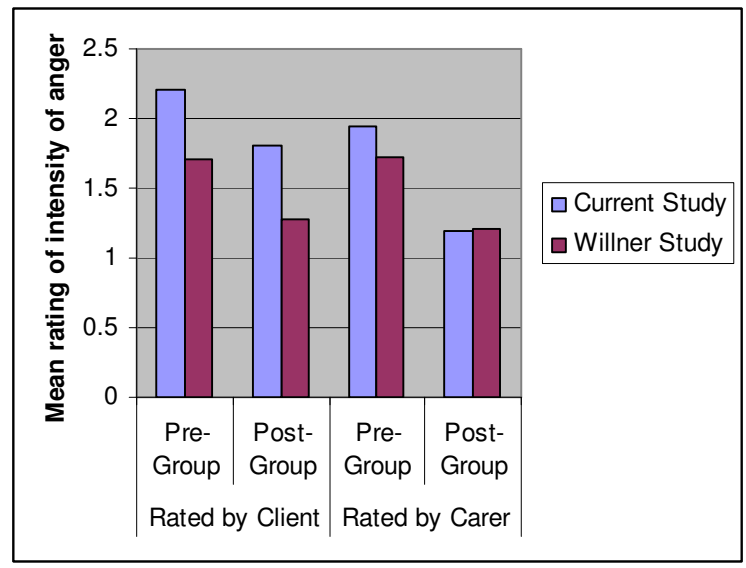

\section{Qualitative Feedback}

In our final session, we asked the group to talk about what they had gained from coming to sessions. 
Rosa told us that the group had helped when she was feeling upset. She told us that she liked the size of the group as she felt more comfortable talking and it was easier to follow what others were saying. She told us that she found distressing situations 'less confusing' since coming to the group as she didn't know what she could do in these situations before, but now was pleased she had options. She didn't know what standing up for yourself/assertiveness was before starting the group, and she was particularly pleased to have learnt these skills as she felt she could use them with her sister.

Lee told us that although he was nervous at the start, as weeks went by, he found the group increasingly useful. He told us that walking away was a skill he adopted a lot more since starting the group, and felt it was useful as it gave him 'space to calm down'. He liked the relaxation CD but found it hard to fit into his life. He told us he was also benefiting from re-thinking the situation as a way of preventing him from getting angry. He told us that he particularly enjoyed the fizzy bottle demonstration (likening the build-up of anger to shaking up carbonated drinks) and it stuck in his head as a way of thinking about anger. He felt that the group had increased his selfconfidence and gave him better skills around how to act in situations. Interestingly, he told us that he was drinking more water as a result of coming, which was something that we did in the break, and he felt hydration impacted his anger levels.

Susan told us that she liked the idea of counting to ten, although admitted that she had not yet used it in a provocative situation. The main thing she seemed to get out of coming to the group was taking part in the relaxation, which she told us she also did at home and intended to use in the future. She said that she enjoyed coming and that there wasn't anything she didn't enjoy.

In discussions with family members when completing the measures, Rosa's mum told us that she was no longer 'stomping' or banging doors, and that she was now more able to let smaller frustrations 'go over her head'. Lee's mum told us that he was more likely to walk away since attending the group and is also banging doors less.

\section{Discussion}

It can be seen in all measures (self report intensity, carer report intensity and carer report frequency) that there was a drop in the scores for all three clients in the group.

While no formal statistical tests were carried out on the data, the results for the PI (intensity) were comparable to those found in the Willner et al. (2002) paper, where statistically significant results (at the $p<0.05$ level) were found. Frequency of anger was not measured in the Willner study however.

For intensity of anger experienced, the improvements seen are actually larger than they appear to be. While it may seem that the ideal score should be 0 (no anger felt), a normal response is to feel anger in the situations asked about (e.g. someone cutting in front of you in a queue or being given cold food in a restaurant). Indeed, the aim of the group was not to suppress anger entirely but to be able to express it appropriately.

For frequency, the improvements that would be seen in the clients' lives are larger than the small numbers seen in the results would entail. As the scores are means across 25 different situations, the change in mean frequency of feeling angry (see 
table 2) would actually mean that the clients are losing their temper many times fewer per month.

The group was smaller than intended. However, as seen in the qualitative feedback, the small size helped to engender a supportive atmosphere where the clients felt confident in speaking. It also allowed each client more time than they would have had otherwise to talk about the anger-provoking situations they had experienced over the previous week. Rosa, who had ASD and it is generally found that people with ASD can commonly find places with lots of people in quite overwhelming, distracting and intimidating, so the small group number was to her benefit.

\section{Reflections}

The use of two facilitators, while it may be considered inefficient in terms of use of resources, did have a number of advantages. When talking through a topic, we managed to co-ordinate activity to simultaneously complement the intent of the other, and would be able to introduce other ideas if the other was struggling. Our debrief sessions conducted after each group gave us an opportunity to question some of our negative thoughts around our performances and provided us useful chances to find out how we were perceived by the other in clinical work. In working together, we could pick up ideas from one another around how we could shape our clinical work in the future. We also used reflection to enhance how we facilitated the group. For example we explored our assumption that the clients were beginning to experience the group as slightly boring in the middle stages. On reflection, it emerged that the extensive repetition had in fact activated our own feelings of boredom and had been interpreted as their boredom. This could well be impacting how we facilitated the group. We combated this by becoming more energetic and creative to incite our own interest.

\section{Future Improvements}

For the same reasons highlighted in the Willner et al. (2002) study, there are some weaknesses with the interpretation of the results from the group. The assessment instruments used were not ideal as they were entirely based on 'what if?' questions with no direct assessment of what a client would do in such a situation. The instruments used also have very little published information about them that would validate them. Additionally, the instruments may underestimate change. While it was made explicit at the start of the assessments that the questions were to be answered in reference to the present or previous couple of weeks, sometimes the carers answered the questions in reference to the past. However, this may have been unavoidable in some instances as the client may not have come across the situation asked about in the last couple of weeks.

Research indicates that carer involvement in similar interventions for people with a learning disability yields better outcomes (Willner, 2006). For our three regular group members, this was not possible due in one case to independent living, for the second in family members not being available at the time of the group and in the third, being part of a family who appeared ambivalent about the treatment and possible benefits. However even without this, outcomes appear positive and comparable to the published RCT treatment group.

Ideally a 3 month follow up assessment would have been completed, but due to the one facilitator's placement coming to an end and the other facilitator leaving his current post, this would not possible. 


\section{Summary}

A small anger management group for clients with a learning disability was conducted using cognitive behavioural techniques. It was shown to have benefited the clients in both reducing the frequency of times they felt angry and how intensely they felt angry in provocative situations, as rated by their carers and in self report. The results found were comparable to the results found in a randomised control trial conducted by Willner et al. (2002). 


\section{References}

Baddeley, A; Longman, D. 1978. The Effect of Length and Frequency of Training Session on the Rate of Learning to Type. Ergonomics, 21(8), 627-635.

Benson, B; Johnson-Rice, C; Miranti, S. 1986. Effects of Anger Management Training with Mentally Retarded Adults in Group Treatment. Journal of Counselling \& Clinical Psychology, 54, 728-729.

Black, L. \& Novaco, R. (1993). Treatment of anger with a developmentally handicapped man. In R. Wells and V. Gianetti (Eds.), Casebook of the brief psychotherapies. pp143-158. New York: Plenum.

Department of Health 1996. Promoting Clinical Effectiveness 1996: A Framework for Action Through the NHS. NHSE: Leeds.

Harris, P. 1993. The Nature and Extent of Aggressive Behaviour Amongst People with Learning Disabilities (mental handicap) in a Single Health District. Journal of Intellectual Disability Research, 37, 221-242.

Kiely, J; Pankhurst, H. 1998. Violence Faced by Staff in a Learning Disability Service. Disability \& Rehabilitation, 20, 81-89.

Mead, P. 2000. Clinical Guidelines: Promoting clinical effectiveness or a professional minefield? Journal of Advanced Nursing, 31(1), 110-116.

Moore, E; Adams, R; ELsworth, J. Lewis, J. 1997. An Anger Management Group for People with a Learning Disability. British Journal of Learning Disabilities, 25, 53-57.

Novaco, R. 1975. Anger Control: The Development and Evaluation of an Experimental Treatment. Lexington: DC Health.

Novaco, R. 1979. The Cognitive Regulation of Anger and Stress. In P. Kendall and C. Hollon (Eds.), Cognitive Behavioural Interventions: Theory, Research \& Procedures. pp. 203-206. New York: Academic Press.

Novaco, R. 1994. Anger as a Risk Factor for Violence Among the Mentally Disordered. In J. Monahan and H. Steadman, Violence \& Disorder: Developments in Risk Assessment. pp. 21-59. Chicago: University Chicago Press.

Novaco, R.W; Ramm, M \& Black, L. 2000. Anger Treatment with Offenders. In C. Hollin (ed), Handbook of Offender Assessment \& Treatment, 281-296, Chichester, UK: Wiley.

Rose, J; West, C. 1999. Assessment of Anger in People with Learning Disabilities. Journal of Applied Research in Intellectual Disabilities, 12, 211-214.

Rose, J; West, C; Clifford, D. 2000. Group Interventions for Anger in People with Learning Disabilities. Research in Developmental Disabilities, 21, 171-181.

Sinason, V. 1992. Mental Handicap and the Human Condition: New Approaches from the Tavistock. London: Free Association Books.

Willner, P. 2005. The Effectiveness of Psychotherapeutic Interventions for People with Learning Disabilities: A Critical Overview. Journal of Intellectual Disability Research, 49(1), 73-85. 
Willner, P. 2006. Readiness for Cognitive Therapy in People with Learning Disabilities. Journal of Applied Research in Intellectual Disabilities, 19(1), 5-16.

Willner, P; Jones, J; Tams, R; Green, G. 2002. A Randomised Controlled Trial of the Efficacy of a Cognitive-Behavioural Anger Management Group for Clients with Learning Disabilities. Journal of Applied Research in Intellectual Disabilities, 15, 224-235 